\title{
Pesquisa de Clima Organizacional: um estudo de caso
}

\author{
Research of Ognanizational Climate: a case study
}

\author{
Mayara Alexandre ${ }^{1}$ \\ ${ }^{1}$ E-mail: $\underline{\text { maiaraalexandre15@,hotmail.com }}$
}

\begin{abstract}
Resumo: O mundo das organizações está cada vez mais competitivo. As empresas precisam ser resilientes, buscando fatores que as diferenciem dos seus concorrentes. $\mathrm{O}$ fator humano é uma ferramenta poderosa nas mãos de gestores que tenham a capacidade de lidar com pessoas e de transformá-las em parte da sua estratégia no alcance dos objetivos organizacionais. O gestor deve atentar para as variáveis do ambiente interno e externo da empresa e como os seus colaboradores irão reagir a estas interações. Estas mudanças ambientais podem afetar positiva ou negativamente o desempenho individual de cada colaborador e, consequentemente, toda a equipa. A Pesquisa de Clima Organizacional mensura fatores que influenciam no clima e avalia os resultados de forma a investigar as suas origens. Este trabalho irá analisar a ingerência do ambiente organizacional nos seus colaboradores e como o clima organizacional pode interferir nos seus comportamentos e na motivação pessoal e profissional. Será aplicado um questionário de abordagem descritiva para avaliar os resultados da Pesquisa de Clima Organizacional.
\end{abstract}

Palavras-chave: Comportamento Organizacional; Clima Organizacional; Pesquisa de Clima Organizacional.

Abstract: The world of organizations is increasingly competitive. Companies need to be resilient, looking for factors that set them apart from their competitors. The human factor is a powerful tool in the hands of managers who have the ability to deal with people and turn them into part of their strategy in achieving organizational goals. The manager must pay attention to the internal and external environment variables of the company and how its employees will react to these interactions. These environmental changes can positively or negatively affect the individual performance of each employee and, consequently, the entire team. The Organizational Climate Survey measures factors that influence the climate and evaluates the results in order to investigate their origins. This work will analyze the interference of the organizational environment in its employees, and how the organizational climate can interfere in their behavior and personal and professional motivation. A descriptive approach will be applied to evaluate the results of the Organizational Climate Survey.

Keywords: Organizational Behavior; Organizational Climate; Organizational Weather Research. 


\section{pontěditora}

\section{INTRODUÇÃO}

Adaptar-se a um ambiente organizacional competitivo e em constante mudança é um desafio cada vez mais atual na administração moderna. Segundo Moreira (2008), apesar destas mudanças antecederem o progresso, a transformação na forma e/ou estado das coisas, seja para melhor ou não, afetam diretamente as pessoas e por consequência o seu comportamento.

Para Moreira (2008, p. 8), “as mudanças decorrentes dos fatores externos e de alguns fatores internos da empresa afetam diretamente o comportamento dos trabalhadores de forma positiva ou negativa" e, com isso, o clima organizacional.

O clima da organização é um importante conceito para um gestor, porque é através do estabelecimento de um clima organizacional adequado que o gerente pode estabelecer as condições motivadoras no ambiente de trabalho. A eficácia da organização pode ser aumentada criando-se um clima organizacional que satisfaça ás necessidades dos membros da organização (MOREIRA, 2008, p. 19)

Como analisa Johann (2013), o clima organizacional demonstra o grau de satisfação dos colaboradores no ambiente de trabalho, que é indicado tanto por factores materiais quanto por factores emocionais que forma o ambiente de trabalho.

A empresa em estudo, é uma organização de médio porte, localizada na região noroeste de Belo Horizonte, Minas Gerais. É formada por três sócios e atua há mais de 30 anos no mercado médico-hospitalar, desenvolvendo um trabalho de propaganda médica, consultoria, distribuição e logística. Trabalha com divulgação e distribuição de produtos de grandes empresas, parceiras nacionais e multinacionais. A sua estrutura é aprovada e licenciada pela Agência Nacional de Vigilância Sanitária, a ANVISA e demais órgãos competentes.

A sua Missão consiste em divulgar e comercializar produtos e também tecnologias que agreguem valor à cadeia hospitalar. Já a sua visão é ser referência como uma organização com know-how na área hospitalar. Entre os seus valores, destaca-se por ser uma empresa que se preocupa com o bem estar dos seus colaboradores, através de políticas motivacionais, e que se orgulha em investir em pessoas. 


\section{pontěditora}

Para Moreira (2008), o estudo do clima organizacional permite identificar e promover ações de melhorias que subsidiam o equilíbrio entre a satisfação do colaborador e o desempenho que se espera da organização para que a mesma alcance os objetivos. Ainda segundo o autor acima, "através da pesquisa de clima organizacional, os colaboradores expressam suas opiniões, contribuem para melhoria do ambiente de trabalho". Assim, o problema deste estudo é: Qual a percepção dos funcionários internos da empresa em estudo sobre o clima organizacional de acordo com a Escala de Clima Organizacional (ECO)?

O objetivo geral deste estudo é identificar a perceção do clima organizacional dos funcionários internos da empresa pesquisada de acordo com a Escala de Clima Organizacional (ECO). Os objetivos específicos são:

- Identificar o perfil dos funcionários pesquisados;

- Identificar os cinco factores da escala ECO;

- Propor no final da pesquisa um plano de ação de melhorias.

Este estudo justifica-se pela relevância do tema e pela importância social e económica, pois, segundo Johann (2013), o clima organizacional é o que mensura a perceção dos colaboradores em relação à atmosfera emocional do ambiente de trabalho. Além disso, Luz (2010) pondera através da pesquisa de clima que as organizações podem avaliar e entender o que pensam e sentem os seus colaboradores, em relação às diferentes variáveis que afetam o clima, tais como: salário, trabalho, condições de segurança no trabalho, entre outras.

Tem relevância também para a empresa pesquisada porque através da elaboração da pesquisa organizacional, pretende-se elaborar um indicador que proporcione resultados para avaliar como as pessoas e organizações interagem, e como isso reflete nos resultados da empresa. Torna-se, assim, o factor humano um diferencial competitivo.

\section{REFERENCIAL TEÓRICO}

$\mathrm{Na}$ construção desse referencial foram pesquisados vários autores e selecionados os assuntos referente ao tema e problema pesquisado: Gestão de Pessoas; Cultura

$\mathrm{e}^{3}$ - Revista de Economia, Empresas e Empreendedores na CPLP | Volume 4 | Número 1 


\section{pontěditora}

Organizacional; Clima Organizacional; Pesquisa de Clima Organizacional; Comportamento Organizacional.

\subsection{Gestão de Pessoas}

Para se entender as diretrizes e o conceito da pesquisa de clima organizacional precisamos primeiramente compreender o que é "organização", o que é "clima organizacional", e como influenciam os objetivos da empresa.

Segundo Spina, Gnoto e Pelacani (2012), “organização” é um sistema onde se olha para o futuro, é um sistema baseado nas decisões através de um olhar criativo e inovador. É de responsabilidade da mesma proporcionar aos seus colaboradores recompensas para motivá-los ao crescimento.

Já de acordo com Nascimento (2008), as organizações no futuro estarão voltadas para a missão e inovação, onde se busca demonstrar vantagem e novas estratégias para resistir a um ambiente externo em constante mudança.

A gestão de pessoas tornou-se mercado tecnológico e competitivo, a maior estratégia das empresas. Xavier (2006) afirma que, mesmo com todos estes avanços, a solução dos problemas e dos desafios organizacionais continua nas mãos dos colaboradores.

Xavier (2006) corrobora que, à medida que a organização entende e conhece melhor as expetativas e comportamentos do seu quadro de pessoal, ela poderá adotar medidas que auxiliem a prover um ambiente produtivo e para ajudar que todos se unam em prol de um objetivo maior, atingindo as metas da empresa.

Ainda segundo o autor acima, as mudanças rápidas na sociedade afetam pessoas e organizações em quatro aspetos:

- Económico: queda de vendas e/ou aumento de custos, devido ao surgimento de uma nova tecnologia. Afeta e empresa que venderá menos e os colaboradores que podem ser mandados embora como consequência.

- Financeiro: A empresa que vende menos terá problemas de caixa e o colaborador será afetado, pois poderá ter seu salário reduzido. 


\section{pontěditora}

- Operacional: Dificuldades operacionais ocorrem para adaptar a estas mudanças, por exemplo, corte de pessoal, mudanças na carga horária, etc.

- Psicossociais: Quando as pessoas começam a ficar tensas, sendo que com as dificuldades vêm os conflitos, desequilíbrio emocional, etc.

\subsection{Cultura Organizacional}

Siqueira (2008), diz que a Cultura Organizacional é o envolvimento dos colaboradores e da organização nos valores e filosofia da empresa. É o conjunto de ideologias e crenças que serve para resolver problemas de integração.

Ainda de acordo com o autor acima, a Cultura Organizacional manifesta-se em três diferentes aspetos:

- Artefatos visíveis: Arquitetura, modo de vestir, linguagem, tecnologia, entre outros. Tudo aquilo que é visível e de fácil observação.

- Valores: Comportamento justificativo para o modo de ser da organização.

- Pressupostos básicos: Crenças e perceções responsáveis sobre como os membros da organização se sentem e pensam em relação á mesma.

Basicamente, Siqueira (2008) indica que a cultura organizacional se manifesta através das pessoas da organização. O que torna o processo de cultura dentro de uma empresa possível é o facto de que as pessoas as transmitem e, através de sua percepção, tornam eficiente a sua disseminação para outros colaboradores.

Segundo Moreira (2008), a cultura expõe e determina quais serão as características da organização: "Identifica os aspectos que impactam positivamente e os obstáculos ao processo de desenvolvimento no universo empresarial em constante mudança" (MOREIRA, 2008, p.22).

Porém, Moreira (2008) acrescenta algumas características importantes na formação da cultura organizacional. São elas:

- Ritos e cerimónias; 


\section{pontěditora}

- Histórias e mitos;

- Tabus;

- Heróis;

- Normas;

- Processos de comunicação.

A cultura organizacional pode ser compreendida como o comportamento da organização, ou seja, os valores, as normas, os processos, os ideais, a missão e os objetivos existentes na corporação. É a partir dela que se coloca ordem na empresa, é nela que os colaboradores irão se basear para desenvolverem suas normas de conduta e atividades e é através da cultura, também, que se construirá um ambiente de trabalho sadio. (MOREIRA, 2008, p. 23)

Ele afirma também que a Cultura Organizacional deriva do fundador da empresa, das suas filosofias e crenças, e que isto é transmitido para os demais colaboradores. Ainda de acordo com Moreira (2008), a cultura leva muito tempo para ser construída e as mudanças no clima de trabalho influenciam também na cultura organizacional que pode levar anos para chegar ao seu projeto final

Segundo Moreira (2008), os dirigentes têm muita influência na cultura organizacional e, portanto, no clima organizacional. Assim, é necessário que logo no processo seletivo seja disseminada a cultura organizacional, para que seja feita uma avaliação adequada do perfil do candidato, para avaliar se o mesmo irá se encaixar nos padrões culturais da empresa.

As empresas devem associar a cultura como forma de se manterem competitivas no mercado. Moreira (2008) afirma que ter vantagem competitiva é fundamental para conquistar novos clientes e atrair novos.

E como estratégia ter uma cultura organizacional saudável, que esteja de acordo com o que está acontecendo no mundo moderno, é fundamental para que a empresa planeie metas eficazes para o sucesso a longo prazo. 


\section{pontěditora}

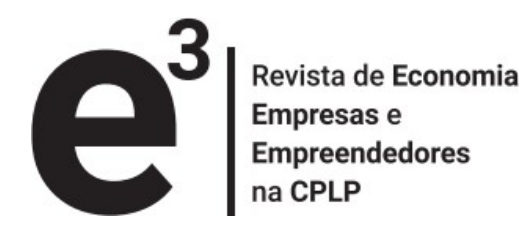

\subsection{Clima Organizacional}

De acordo com Siqueira (2008), para entender como o ambiente de trabalho e as suas constantes mudanças influenciam os seus colaboradores e o comportamento em relação a este ambiente, temos que falar de clima organizacional. Ainda de acordo com Siqueira (2008, p. 31), Clima Organizacional refere-se "a influências do ambiente interno de trabalho sobre o comportamento humano".

As organizações precisam compreender como os seus colaboradores interagem e percebem estas mudanças organizacionais, e como isso afeta o seu comportamento. Os colaboradores estão diariamente expostos a transformações e estímulos vindos das rápidas mudanças no ambiente externo da organização, tendo visões e reações diferentes a essas dinâmicas.

Não se deve confundir clima organizacional e avaliação de satisfação, esses se diferem conforme abaixo:

Clima organizacional é formado por percepções compartilhadas pelos trabalhadores. Na avaliação de satisfação verifica-se o quanto o empregado 'gosta ou não' de determinados aspectos do ambiente organizacional; na avaliação de clima organizacional verifica-se a percepção, a descrição da ausência ou presença destes aspectos. Portanto clima organizacional é uma variável da natureza cognitiva, enquanto satisfação no trabalho é uma atitude e, como tal, composta por elementos afetivos e cognitivos (SIQUEIRA, $2008 \mathrm{p}$. 32)

Moreira (2008) destaca que o clima organizacional não é palpável ou visto, mas pode ser constatado através da perceção.

O clima organizacional é um ambiente formado pelas pessoas da organização, provocando interações que interferem na motivação e comportamento deste grupo.

Clima organizacional e cultura organizacional são termos diferentes, mas que se complementam. Robbins (2009) certifica isso afirmando que cultura organizacional é "um sistema de valores compartilhado pelos membros que diferencia uma organização das demais". 


\section{pontěditora}

Luz (2007) ressalta que o Clima organizacional é um reflexo do ambiente. Dito isso, difere-se da cultura, pois enquanto o primeiro demonstra como é percebido o ambiente da empresa pelos colaboradores, o segundo demonstra como este ambiente vai ser construído, as suas regras padrão, etc.

Luz (2007, p. 13) descreve clima organizacional como "a atmosfera psicológica que envolve num dado momento a relação entre a empresa e seus funcionários".

\subsection{Pesquisa de Clima Organizacional}

Para Johann (2013), a pesquisa de clima organizacional deve ser usada como uma ferramenta de diagnóstico, pois através dela pode ser uma base de como os colaboradores estão percebendo a organização e sua dinâmica.

É necessário para o alcance dos objetivos organizacionais que todos os colaboradores entendam a importância das metas da empresa e estejam comprometidos a partilhar os valores, a missão e visão da empresa.

\subsection{Comportamento Organizacional}

Robbins (2009) ressalta a diferença entre comportamento e atitude. A atitude será uma pré-ação, ou seja, é aquilo que antecede o comportamento. Por sua vez, o comportamento é o reflexo da atitude. Para que a organização esteja preparada para os novos mercados, desafios, entre outros, a sua atitude em relação às mudanças deve ter em vista transformá-las em oportunidades.

Robbins (2009) destaca que o comportamento organizacional é, também, classificado como habilidades humanas dentro da organização, é o estudo do que fazem e como o comportamento humano afeta o seu desempenho na organização.

O comportamento Organizacional é um campo de estudos que investiga o impacto que indivíduos, grupos e a estrutura tem sobre o comportamento dentro das organizações com o propósito de utilizar este conhecimento para melhorar a eficácia organizacional. (ROBBINS, 2009 p. 6). 


\section{pontěditora}

Robbins (2009) argumenta que, para os executivos, compreender o comportamento organizacional é de suma importância para que os mesmos possam se adaptar as rápidas mudanças do mundo globalizado e cada vez mais competitivo. O comportamento organizacional traz desafios, mas que se tornam oportunidades e soluções para estes novos cenários organizacionais.

Pode-se destacar, segundo Robbins (2009), que o estudo do comportamento organizacional proporcionará aos empresários a capacidade de manter a sua equipa de trabalho qualificada e comprometida, o que como consequência os tornará mais competitivos. Assim, torna-se necessário práticas de melhoria contínua e gestão da qualidade. Para isso, é necessário que os colaboradores passem por treinos e constantes avaliações que os tornem aptos para aprender novas habilidades.

Todas estas mudanças necessárias à organização não seriam possíveis sem a inclusão dos colaboradores, pois, além da força de trabalho para a execução destas mudanças, eles também se tornarão coparticipantes do planeamento.

Nascimento (2008) pondera, por sua vez, que o comportamento organizacional é influenciado pela cultura da empresa. E a cultura, por sua vez, é influenciada por factores educacionais, familiares, sociais, etc. Sendo assim, trabalhar com a diversidade é um papel desafiador para os novos gestores. Estes devem "criar uma cultura organizacional focada para promoção da liberdade de expressão e que fortaleça as relações, com uma contribuição efetiva na organização"(NASCIMENTO, 2008 p. 74).

Chiavenato (2014) pondera que o comportamento organizacional é o estudo dos indivíduos que compõem a organização e o seu ambiente, com o objetivo de analisar as variáveis que podem interferir no comportamento humano individual e que podem ter impacto no ambiente organizacional.

Ainda segundo o autor, para compreender o comportamento organizacional é preciso atentar dois aspetos: os superficiais e perceptíveis, e os profundos e imperceptíveis.

Dentre os aspetos visíveis pode-se citar: as estratégias e objetivos, políticas, tecnologia, estrutura, comando, etc. Já dentre os aspetos invisíveis estão: as atitudes, percepções, interações dos grupos informais e os conflitos interpessoais.

$\mathrm{e}^{3}$ - Revista de Economia, Empresas e Empreendedores na CPLP | Volume 4 | Número 1 


\title{
pontěditora
}

\begin{abstract}
Ademais, o CO se defronta com desafios importantes, como o nível de mudança no mundo e no ambiente dos negócios, nas caracteristicas da força de trabalho que atua nas organizações, nas expectativas dos clientes e consumidores, nas próprias organizações, no comportamento dos dirigentes e gerentes e, sobretudo, no fato de que o conhecimento está se tornando progressivamente o principal fator de produção. Tudo isto torna o estudo da CO cada vez mais importante, tanto pata o sucesso organizacional quanto para o sucesso pessoal daqueles que lidam com organizações (CHIAVENATO, 2014, p. 19).
\end{abstract}

\section{METODOLOGIA}

A metodologia utilizada foi a pesquisa descritiva com um estudo de caso e o método quantitativo. Segundo Lakatos e Marconi (2003 p.155), “A pesquisa, portanto, é um procedimento formal, com método de pensamento reflexivo, que requer um tratamento científico e se constitui no caminho para conhecer a realidade ou para descobrir verdades parciais". Kauark, Manhães e Medeiros (2010) acrescentam que pesquisa é a busca por solução de algum problema. Seria produzir resposta para algo ou alguém.

Para Kauark, Manhães e Medeiros (2010), é importante classificar os tipos de pesquisa para que o pesquisador identifique os instrumentos e procedimentos para elaborar a sua investigação. Para Vergara (2006), a pesquisa pode ser classificada de duas formas: quanto aos fins e quanto aos meios. Quanto aos fins, a pesquisa feita neste trabalho é a descritiva, que procurou informações para as variáveis relacionadas à pesquisa de clima organizacional.

A modalidade de pesquisa descritiva, conseguiu mensurar os resultados por meio de questionário:

Pesquisa Descritiva: visa descrever as características de determinada população ou fenômeno, ou o estabelecimento de relações entre variáveis. Envolve o uso de técnicas padronizadas de coleta de dados: questionário e observação sistemática. Assume, em geral, a forma de Levantamento (KAUARK; MANHÃES; MEDEIROS; 2010, p. 28)

A pesquisa foi realizada na empresa já citada como instrumento de estudo. $\mathrm{O}$ questionário foi aplicado a 15 dos 23 colaboradores internos da empresa, pois não foi obrigatório que todos respondessem, tendo a adesão de $65 \%$ do universo pesquisado. Não foi necessária amostra. 


\section{pontěditora}

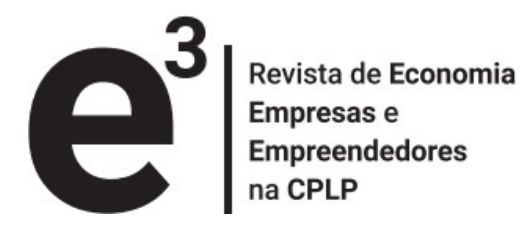

Os sujeitos deste trabalho foram os colaboradores internos, devido à facilidade de acesso do autor do estudo aos mesmos. Dito isso, este trabalho usou como padrão o critério de acessibilidade proposto por Vergara (2006).

A técnica utilizada foi um questionário, que para Kauark, Manhães e Medeiros (2010) é um instrumento de coleta de dados que é elaborado pelo pesquisador e é preenchido por quem ele está sendo aplicado. Deve-se atentar para uma linguagem simples e direta, de forma que o informante entenda com clareza as perguntas. Antes da aplicação do questionário deve ser feito um pré-teste para não haver erro e para que o aplicador possa corrigir possíveis erros.

Questionário é um instrumento de coleta de dados, constituido por uma série ordenada de perguntas, que devem ser respondidas por escrito e sem a presença do entrevistador. Em geral, o pesquisador envia o questionário ao informante, pelo correio ou por um portador; depois de preenchido, o pesquisado devolve-o do mesmo modo. Junto com o questionário deve-se enviar uma nota ou carta explicando a natureza da pesquisa, sua importância e a necessidade de obter respostas, tentando despertar o interesse do recebedor, no sentido de que ele preencha e devolva o questionário dentro de um prazo razoável (LAKATOS; MARCONI, 2003, p.201).

Foi aplicado um questionário aos colaboradores internos que aderiram à pesquisa: a Escala de clima organizacional - ECO. A análise de dados foi a quantitativa, traduzida em informações que foram classificadas e analisadas. "Requer o uso de recursos e de técnicas estatísticas (percentagem, média, moda, mediana, desvio-padrão, coeficiente de correlação, análise de regressão)" (KAUARK; MANHÃES; MEDEIROS, 2010, p. 26).

\section{RESULTADOS}

O questionário utilizado para mensurar o clima organizacional foi a Escala de Clima Organizacional (ECO) para que se pudesse avaliar a perceção dos colaboradores sobre o clima organizacional e as suas influências. A ECO foi aplicada de forma anónima, ou seja, não foi revelada a identificação dos funcionários participantes.

Segundo Martins (2008), a ECO é uma escala que possui o objetivo de avaliar e mensurar a visão do funcionário sobre o clima organizacional presente na instituição que ele desenvolve as suas atividades. A escala final validada, que foi utilizada na 


\section{pontěditora}

pesquisa, é composta por 63 itens de avaliação onde o colaborador tinha as seguintes opções: 1 - Discordo totalmente; 2 - Discordo; 3 - Nem concordo, nem discordo; 4 Concordo; 5 - Concordo Totalmente; que estão divididos em 5 blocos de questionamentos, a fim de levantar dados sobre 5 factores, são eles: Factor 1, com 21 itens (Apoio da chefia e da organização); Factor 2, com 13 itens (Recompensa); Factor 3, com 13 itens (Conforto físico); Factor 4, com 9 tens (Controle e pressão); e Factor 5, com 7 itens (Coesão entre colegas). A ECO: Escala de Clima Organizacional é compostas por 5 factores e a análise de dados também foi feita por factor. Assim, obteve-se uma média factorial para cada um dos cinco factores.

O resultado foi obtido somando-se os valores marcados pelos colaboradores em cada item e dividindo-se pelo total de itens, ou seja:

Para o Fator 1, apoio da chefia e da organização, somam-se os valores das respostas aos itens 1 até o 21 e divide-se o resultado por 21. Depois, somam-se as médias de cada respondente em cada fator e divide-se pelo número de respondentes e assim sucessivamente. Os resultados das médias fatoriais deverão ser sempre um número entre 1 e 5 que é a amplitude da escala de respostas. (MOREIRA, 2008, p. 20).

O quadro 1 mostra os factores de avaliação, bem como suas definições, e quais são os itens a quais eles se referem no questionário:

Quadro 1 - Denominações, definições e itens integrantes da ECO

\begin{tabular}{|l|l|l|}
\hline DENOMINAÇÕES & DEFINIÇÕES & ITENS \\
\hline Apoio da chefia e da & $\begin{array}{l}\text { Suporte afetivo, estrutural e operacional da } \\
\text { chefia e da organização fornecido aos } \\
\text { empregados no desempenho diário de suas } \\
\text { atividades no trabalho. }\end{array}$ & 1 ao 21 \\
\hline Recompensa & $\begin{array}{l}\text { Diversas formas de recompensa usadas pela } \\
\text { empresa para premiar a qualidade, a } \\
\text { produtividade, o esforço e o desempenho do } \\
\text { trabalhador. }\end{array}$ & 22 ao \\
\hline
\end{tabular}

$\mathrm{e}^{3}$ - Revista de Economia, Empresas e Empreendedores na CPLP | Volume 4 | Número 1 


\begin{tabular}{|l|l|l|}
\hline Conforto físico & $\begin{array}{l}\text { Ambiente físico, segurança e conforto } \\
\text { proporcionados pela empresa aos } \\
\text { empregados. }\end{array}$ & $\begin{array}{l}35 \text { ao } \\
47\end{array}$ \\
\hline Controle/pressão & $\begin{array}{l}\text { Controlo e pressão exercidos pela empresa e } \\
\text { pelos supervisores sobre o comportamento e } \\
\text { desempenho dos empregados. }\end{array}$ & $\begin{array}{l}48 \text { ao } \\
56\end{array}$ \\
\hline Coesão entre colegas & $\begin{array}{l}\text { União, vínculos e colaboração entre os } \\
\text { colegas de trabalho. }\end{array}$ & $\begin{array}{l}57 \text { ao } \\
63\end{array}$ \\
\hline
\end{tabular}

Fonte: SIQUEIRA (2008, p. 35)

Gráfico 1 - Escala do Clima Organizacional por factores

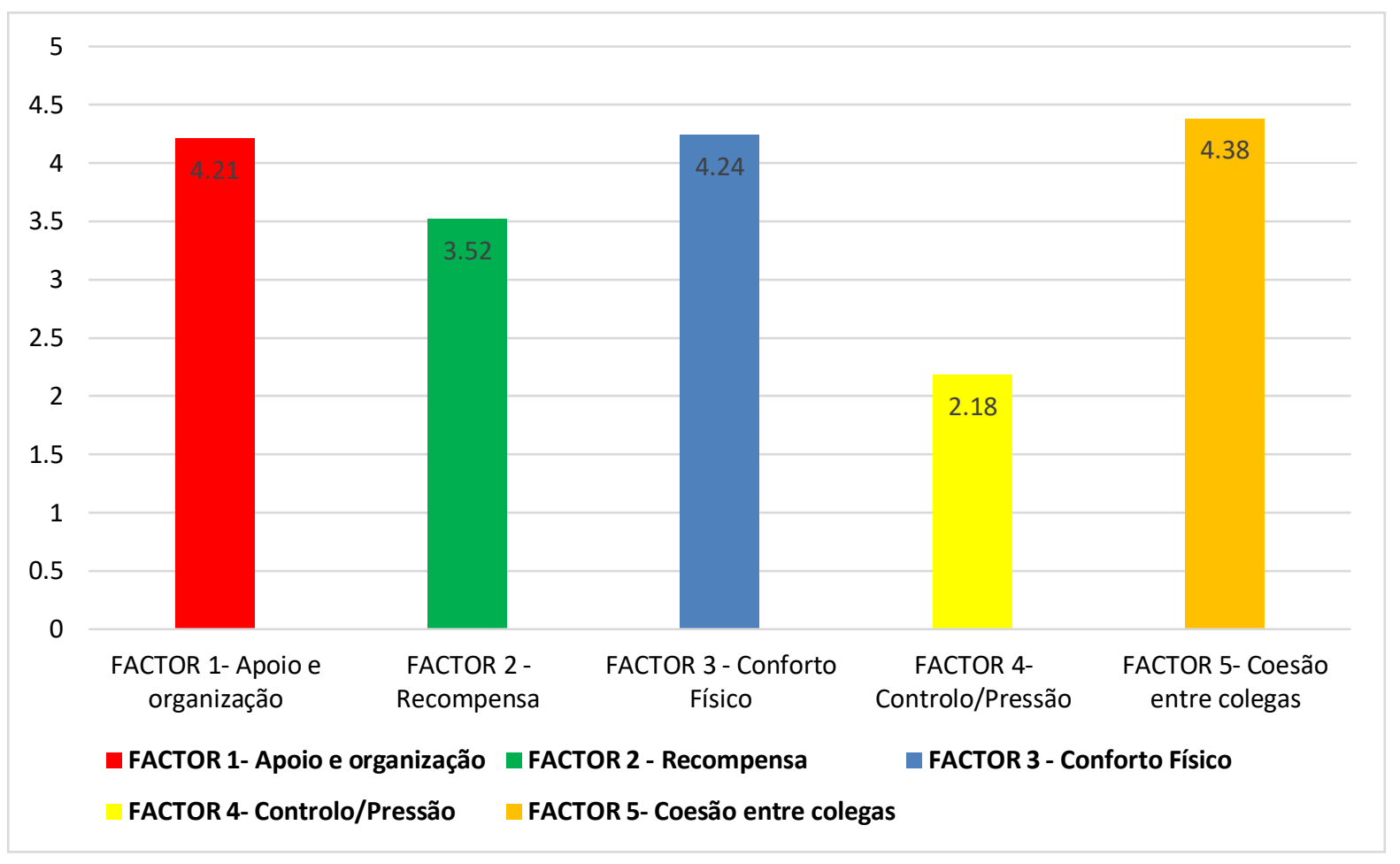

Fonte: Dados da pesquisa (2017)

Factor 1 - Apoio da chefia e da organização: buscou-se analisar o suporte afetivo, estrutural e operacional da organização e da direção e chefia, oferecido aos colaboradores para que os mesmos desempenhem as suas funções e atividades diárias 


\section{pontěditora}

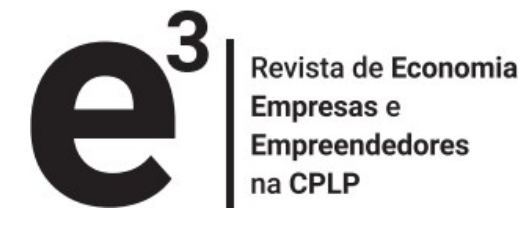

com eficiência e eficácia. Neste quesito, a empresa estudada apresentou um resultado muito satisfatório, alcançando a média de 4,21, onde 5,00 seria nota máxima. Portanto, a perceção dos colaboradores internos sobre o factor "Apoio da chefia e da organização" é de que eles têm um clima neste quesito sustentável para realizar as suas demandas e estão confortáveis em relação ao suporte recebido.

Factor 2 - Recompensa: neste factor analisou-se as formas com que a organização recompensa os seus colaboradores, de forma premiá-los pela qualidade, produtividade e esforço para desempenhar as suas funções. A empresa apresentou, também neste quesito, um resultado satisfatório, alcançando a média 3,52, onde 5 seria a nota máxima. Porém, observou-se que neste factor os colaboradores não estão com um nível de satisfação tão elevado quanto no factor acima. Notou-se que a sua percepção sobre as recompensas deve ser um factor que talvez necessite de atenção por parte da organização.

Factor 3 - Conforto físico: neste quesito analisou-se o ambiente físico, segurança e conforto que a empresa proporciona aos seus colaboradores. A empresa apresentou um resultado muito satisfatório, alcançando a média 4,24, onde 5 seria a nota máxima. Isso apontou que as dependências da organização estão de acordo com expetativa dos seus colaboradores e que eles se sentem confortáveis no seu ambiente de trabalho.

Factor 4 - Controlo/Pressão: analisou-se o controlo e pressão exercidos pela direção e supervisão sobre os colaboradores, comportamento e desempenho. A empresa apresentou um resultado muito satisfatório, pois, ao contrário dos quesitos acima, neste factor quanto menor o resultado demonstra que há um bom clima no ambiente de trabalho, onde não há demasiado abuso de pressão e controlo sobre os colaboradores. A empresa obteve média de 2,18 neste factor.

Factor 5 - Coesão entre os colegas: analisou-se a união, vínculos e colaboração entre os colegas de trabalho. A empresa apresentou um resultado muito satisfatório neste quesito, alcançando média de 4,38, onde 5 seria a nota máxima. A perceção dos colaboradores em relação aos seus colegas de trabalho é excelente. Percebeu-se que nesta empresa há um bom relacionamento entre os mesmos e isso aponta para um bom clima organizacional neste factor. 


\section{pontěditora}

\section{CONSIDERAÇÕES FINAIS}

Após os resultados apresentados, conclui-se que os objetivos foram alcançados e constatou-se que a pesquisa de clima organizacional, utilizando a Escala de Clima Organizacional (ECO), é uma ferramenta valiosa para a compreensão das relações no ambiente organizacional e também no cenário atual de gestão com tantas turbulências económicas e tecnológicas.

Pode-se avaliar que a empresa apresenta um bom clima organizacional, a percepção dos colaboradores sobre a organização em seus múltiplos factores de clima como: apoio da chefia, conforto físico, controlo e pressão, e coesão entre os colegas foi muito satisfatório. Isso aponta que a empresa quer que os seus colaboradores sejam de facto seus parceiros nos alcances dos seus objetivos e se preocupa com o bem estar físico e emocional. Constatou-se na empresa pesquisada que o clima organizacional é ótimo sob o ponto de vista dos colaboradores internos, padrão que demonstra a qualidade da empresa no zelo pelas pessoas e no investimento interpessoal.

Observou-se que a limitação encontrada na pesquisa foi a resistência em se responder a algumas questões relacionadas à recompensa, onde alguns optaram em responder que “nem concordam e nem discordam”, não expressando totalmente a sua opinião.

Após a análise dos resultados obtidos, notou-se que o quesito "recompensa" foi o único em que houve um resultado apenas satisfatório, não que esteja insuficiente, pois não influenciou consideravelmente na escala do clima. Mas seria um factor de atenção, pois, ele pode gerar não apenas insatisfação, mas criar um desconforto emocional nos colaboradores, mesmo que existam outros factores que compensem este desgaste.

Como proposta, sugere-se que a empresa adote um programa de recompensas flexível onde, por exemplo, o colaborador que for premiado pela sua qualidade e produtividade possa escolher, entre as opções propostas pela empresa, um pacote de benefício que melhor atenda a sua necessidade.

Para trabalhos futuros, sugere-se aos académicos de administração que continuem a pesquisar sobre o clima organizacional e a sua influência emocional e no desempenho dos colaboradores. 


\section{pontěditora}

\section{REFERÊNCIAS}

CHIAVENATO, Idalberto. Comportamento Organizacional: a dinâmica do sucesso nas organizações. 3. ed. Barueri: Manole, 2014.

JOHAN, Silvio. Comportamento Organizacional. São Paulo: Saraiva, 2013.

KAUARK, Fabiana; MANHÃES, Fernanda Castro; MEDEIROS, Carlos Henrique. Metodologia da Pesquisa: Um guia prático. Itabuna: Via Litterarum, 2010.

LAKATOS, Eva Maria; MARCONI, Marina de Andrade. Fundamentos de metodologia científica. 5. ed. São Paulo: Atlas, 2003.

LUZ, Ricardo. Gestão de clima organizacional. Rio de Janeiro:Qualitymark, 2007.

LUZ, Ricardo. Gestão do clima organizacional. Rio de Janeiro: Qualitymark, 2010.

MOREIRA, Ellen Gongorra. Clima organizacional. Curitiba: IESDE Brasil S.A., 2008.

NASCIMENTO, Eunice. Comportamento Organizacional. Curitiba: IESDE Brasil S.A, 2008.

ROBBINS, Sepen. Comportamento Organizacional. 11. ed. São Paulo: Person Prentice Hall, 2009.

SIQUEIRA, Mirlene Maria Matias, Medidas do comportamento organizacional: Ferramentas de diagnósticos e de gestão. Porto Alegre: ARTMED, 2008.

SPINA, Afonso; GNOTO, Gilberto; PELACANI, Maria Inez. Psicologia das Organizações. Curitiba: IESDE Brasil S.A, 2012.

VERGARA, S. C. Projetos e Relatórios de Pesquisa em Administração. 7. ed. SãoPaulo: Atlas, 2006.

XAVIER, Ricardo. Gestão de Pessoas na prática. São Paulo: Gente, 2006.

\section{(cc)) EY-NG-SA}

O trabalho $\mathrm{e}^{3}$ - Revista de Economia, Empresas e Empreendedores na CPLP está licenciado com uma Licença Creative Commons - Atribuição-NãoComercial-Compartilha Igual 4.0 Internacional. 